\title{
Development of enterprise information systems
}

\author{
Milan Martinkovič ${ }^{1}$, Branislav Mičieta ${ }^{1}$, Vladimíra Biňasová ${ }^{1}$ \\ Miroslav Fusko ${ }^{1}$ \\ ${ }_{1}$ University of Žilina, Faculty of Mechanical Engineering, Department of Industrial \\ Engineering \\ Univerzitná 8215/1, 01026 Žilina, Slovakia \\ milan.martinkovic@fstroj.uniza.sk \\ branislav.micieta@fstroj.uniza.sk \\ vladimira.binasova@fstroj.uniza.sk \\ miroslav.fusko@fstroj.uniza.sk
}

\begin{abstract}
Annotation: The article deals with the description of the development of systems for production planning and control, which are adapted to the current needs of companies and also to the ongoing fourth industrial revolution. The article describes the gradual development of these systems from the initial systems to the current one's systems, which solve the problem (excess data) that is currently faced by many companies. Due to this problem, several companies may find themselves in a state where they are surrounded by a large amount of data. At the end of the article, the outlook for the future within the development of systems is described and the risk planning module (in the future as a part of the ERP system) is described, which is solved within the dissertation thesis.
\end{abstract}

\section{Introduction}

At present companies must be in good condition and manage flexibly respond to frequently changing requirements of customers. Companies must also be able to respond to unexpected events that may disrupt the production process, or worse, stop production, which may result in reduced customer confidence or loss of customers. Therefore, companies must place particular emphasis on production planning and management and use production planning and control systems, more precisely enterprise resource planning (ERP) information systems.

ERP systems have their advantages and disadvantages (limitations, price, difficulty and length of implementation in the company). Not every company may be comfortable with the system. In the past, the ERP system was used by large companies, but now the manufacturers of ERP systems also focus on small and medium-sized companies. Therefore, research in the field of production planning and control is constantly ongoing.

Companies generate a lot of data every day, which causes a plethora of data, and after a while, the company finds itself in a sea of data and does not know what to do with it and how to use it to its advantage. Because the company does not know how to use this data, it loses money. Therefore, in combination 
with the ERP system, the Business Intelligence (BI) method is used, which can evaluate and make available the necessary information that is helpful for the company $[1,2]$.

\section{ERP system}

The ERP system is an integrated enterprise resource planning system and contains a set of applications that automate the financial, logistics, production and personnel areas. They also help achieve business goals and automate a variety of activities related to business processes inside and out.

The basis of enterprise information systems is a common database, to which, in addition to production, all other areas are connected - trade and marketing, distribution and technology, finance, accounting, suppliers, human resources, etc. From the point of view of information systems solutions, ERP can be defined as a comprehensive software package that allows targeted and efficient management of corporate resources (finance, investment and inventory). In the past, companies solved each area with separate applications, but today they choose an ERP system that allows them to cover all the needs of the company. The ERP system includes all the data and processes of the company and combines them into a whole. To achieve integration, the ERP system uses a number of software modules as well as hardware infrastructures. The basis of a large part of ERP systems is the use of a unified database for data storage. The individual modules then draw from this database $[2,3,4]$.

\subsection{History of ERP system}

ERP development began with the MRP (Material Requirements Planning) system, which means material requirements planning. MRP is a production planning and inventory control system and assists in the integration of information from production plans from inventory and BOM in the calculation of purchase and shipping costs and plans for parts needed to assemble the product. The disadvantage was the integrity of the data. The data had to be accurate when entered into the MRP system, as they could cause serious errors in production and storage.

In the 1970s, an improvement of the MRP system was created. The improvement was in terms of interconnecting the capacity requirements planning module. The MRP II system has been extended with the reverse flow of information from production. The main benefit of the MRP II system is the reduction of the commitment of working capital (approximately 30\%), which is the main problem in terms of production management in companies. Reductions in procurement and maintenance costs can also be expected. The MRP II system has a capacity requirements planning module, with a link to sales management. The disadvantage of the MRP II system was that when planning, the system takes into account unlimited production capacities. Therefore, the proposed plans are checked in modules designed for capacity 
planning. If the inspection reveals that the required capacity requirements are higher than the actual capacities, then a scheduler starts to solve this problem. In the 1990s, there was unprecedented global competition, customer focus and shorter product life cycles. In order to respond to these requirements, companies had to move towards agile (rapid) production of products, continuous improvement of processes and reengineering of business processes. Based on the technological foundations of MRP and MRP II systems, ERP (Enterprise Resource Planning) systems integrate business processes including manufacturing, distribution, accounting, finance, human resource management, project management, inventory management, service, maintenance and transportation, ensuring accessibility, visibility and enterprise-wide consistency. ERP systems are such integrated information systems that are designed to meet the information and decisionmaking needs of the company covering all management functions. All ERP systems in the 1990s used the old on premise model (software can be installed and run on customer's premises). Towards the end of the 1990s, an ERP system was created that was not on premise and was delivered via the Internet [5,6].

At the beginning of 2000, the ERP II system was created. ERP II is defined as Internet software that provides real-time access to ERP. The ERP II system (Figure 1) is strengthened by the modules of supply chain management (SCM), Business Intelligence (BI), E-Business and customer relationship management (CRM).

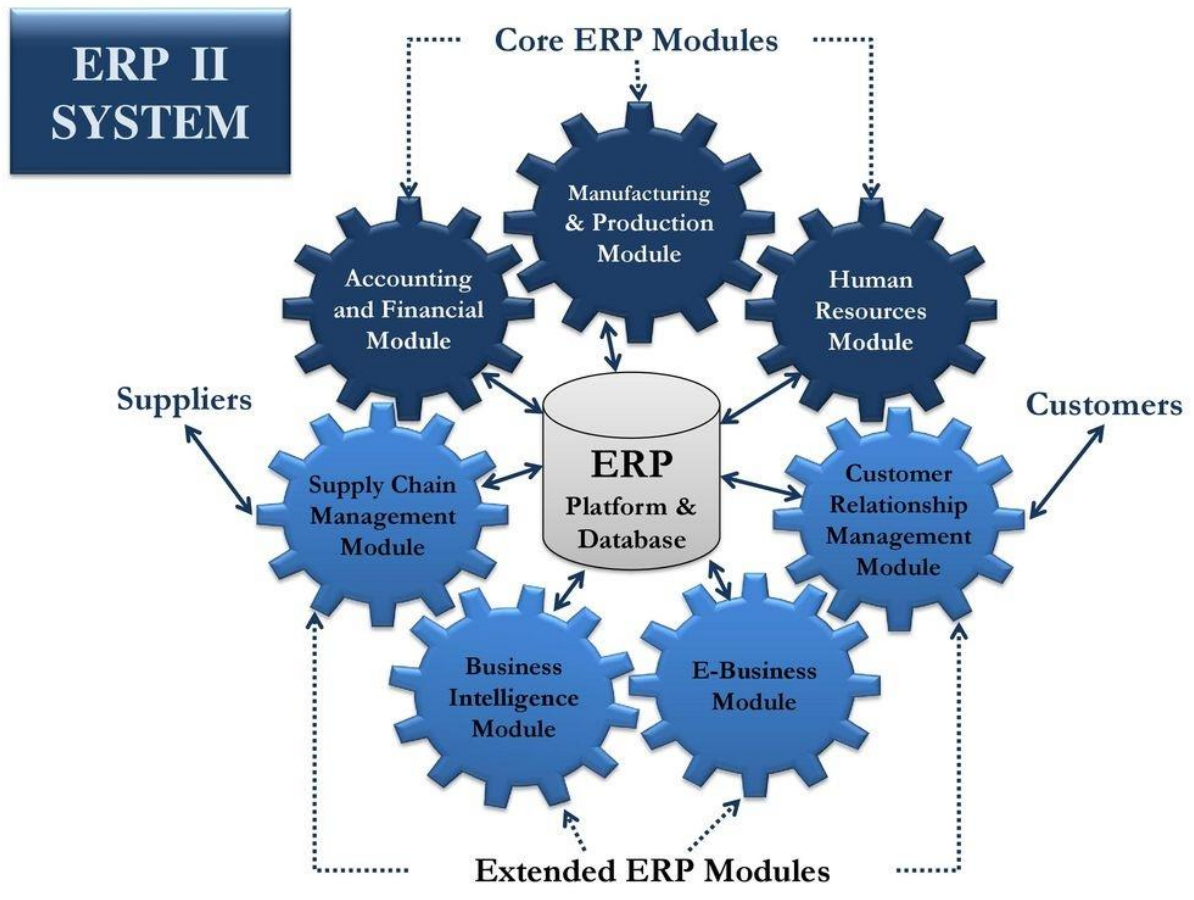

Figure 1 - ERP I/ system model [7]

As mentioned in the introduction, the ERP system in the company collects data, which can result in a surplus of data over time. If the company cannot process this data, the company loses important information that it could use to 
its advantage. Therefore, the Business Intelligence (BI) module was added, which increases the efficiency of the ERP system in terms of data processing. Business Intelligence $(\mathrm{BI})$ is software that collects data from the ERP system, then integrates, analyses and finally presents this data in an easy-to-use and interpretable state. Thanks to Business Intelligence (BI), important information is returned to the company for use and does not remain locked in the ERP system $[5,6,8]$.

\section{$3 \quad$ ERP system currently}

Currently, most companies use the ERP system in combination with other systems (modules). A typical enterprise software configuration includes three large systems - an ERP system, a SCM system (Supply Chain Management) and a CRM system (Customer Relationship Management). All systems are built on top of one or more database system systems (DBMS), ideally, using the same logically integrated database. ERP, SCM and CRM systems are usually standard software that has been adapted to the requirements of the individual organization. Currently, these three types of systems tend to be integrated: the SCM module, for example, will have access to the information available in the ERP system directly or through a common database [3].

Today (since 2010) the concept of ERP III system is used. This system is an improvement of the ERP II system. ERP III is extensive use of the cloud infrastructure, working through social networks with customers, potential buyers, product experts, suppliers, potential suppliers, partners, potential partners, potential employees and other categories of people with whom you need to communicate. ERP III is designed to create businesses without borders. Online interaction in social networks and online business platforms allows companies to respond dynamically to emerging opportunities and challenges, creating a flexible structure based on business processes and projects. The advantage of the cloud is that the ERP III system is not physically installed but sharing is used, and in terms of the data produced by the company, it is less costly to buy space in the cloud than to buy physical storage than it is with data forces.

The ERP III system also uses advanced Business Intelligence (BI). BI no longer provides just standardized dashboards and reports but can compile and display the exact data that a business considers most relevant in a number of areas. $\mathrm{BI}$ is also increasingly distributed throughout the organization. The combination of the cloud infrastructure with $\mathrm{BI}$ allows ERP developers to create dashboards that can be accessed by senior management, end-users, and everyone in between. In addition to viewing, it allows users to manipulate and create a user-oriented information panel that is relevant to them from data sources outside the ERP system. Anyone with authorization has access to and use of relevant data. As an example, an employee operating a machine can view a monitor that shows 
the performance of the equipment and its efficiency. The end-user can quickly visualize the relevant data, as opposed to waiting for the end of the day for all this data to be collected and creating messages that say, "Machine A was much slower on Wednesday than Machine B." Instead, the user can see this in real-time. So when something is wrong, the operator can quickly identify the problem and make changes or seek help - they don't have to wait for trained staff to diagnose problems and disable solutions, which is timeconsuming and costly $[3,8,9]$.

\section{$4 \quad$ Further development of the ERP system}

Current ERP systems cannot answer questions such as what is better to buy, new assets or modernize existing, what and where to build, what and where to buy, what and how to modernize, to what extent repairs and maintenance should be performed, which is more efficient, hire new employees or train existing employees on how to allocate resources to train employees in specific areas.

ERP IV will be prepared to answer these questions by developing cognitive services and big data processing technologies within ERP III. ERP IV does not yet envisage the use of artificial intelligence (AI)(artificial intelligence comparable at the human level), the precondition for its use should be only in ERP V (from 2030 to 2040), or ERP VI (from 2040 to 2050). With the ERP system, a 10-year cycle of generational change is expected. Another aspect that influences the occurrence of artificial intelligence at the human level in business systems is the time of its learning. Although the structure of the required neural network is quite clear, the acquisition of knowledge corresponding to the secondary, bachelor's and engineering/master's degrees in the chosen specialization, as well as some practical experience in terms of actual work can take a long time.

Figure 2 shows the gradual development of ERP systems from the past through the present and with an expected outlook for the future.

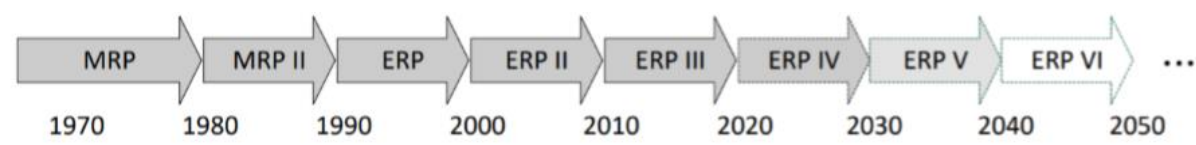

Figure 2 - Expected development of the ERP system [10].

Although ERP III uses industry 4.0 technologies, there is still a lack of a module to identify and analyse the risks that may arise and to develop action plans for these risks. In the event of risks, action plans to eliminate or mitigate the negative impact of those risks would be activated. Only in ERP $\mathrm{V}$ (from 2030) is artificial intelligence assumed to handle this task.

Therefore, a methodology is currently being proposed to protect the assembly plan in view of the risks that may arise. This methodology would be used after 
the assembly plan has been drawn up. The basic methodology will be briefly described in the next chapter [10].

\section{$5 \quad$ Methodology for protection of the assembly plan}

The methodology for the protection of the assembly plan is proposed due to the fact that companies currently lack critical thinking and adaptability in the event of a sudden risk. In some cases, companies forget that there may be a risk, whether from an internal or external environment. Some companies do not take these risks into account when creating the assembly plan, and in the event of a risk, the assembly may be stopped, which will delay the completion of the order and possibly reduce the customer's confidence or loss.

The task of the methodology will be to use modules to create an action plan, which is activated in the event of a risk and mitigates or eliminates its negative impact. In figure 3 shows the state of the assembly plan without the application of the methodology (a) and the expected state after the application of the methodology in the event of a risk (b).

a.

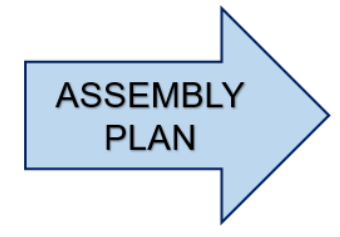

b.

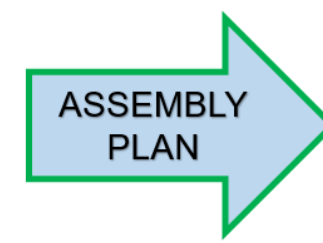

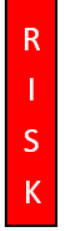
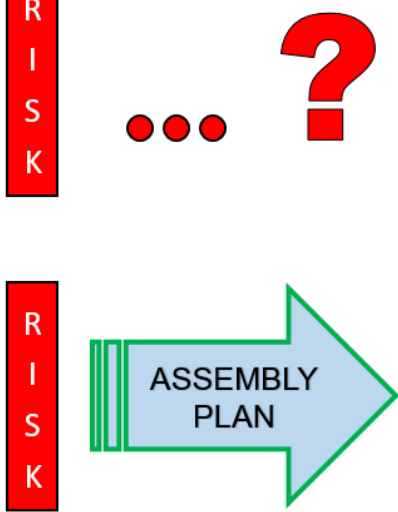

Figure 3 - Assembly plan before and after using the methodology [authors].

Currently, in some companies, in the event of an unexpected risk (for example, failure to supply the necessary material), assembly is stopped and the company finds out what to do in order to return back to production. As the company finds out how to proceed, it loses its time needed to complete the order. In some cases, this unexpected cessation of production (assembly workplaces) can take weeks, depending on the available capacity of the company and the speed of the company to respond to the event. (Figure 3-a)

If, after the assembly plan has been drawn up, the company uses the proposed method to identify potential risks and create ways to deal with those risks, the company would be able to react immediately in the event of a risk. The overall assembly plan would slow down but not stop. The company would try to make the most of this restriction until the impact of the risk is removed and the plan is in its original conditional. (Figure $3-b$ ). 


\subsection{Proposed methodology}

The core of the proposed methodology consists of three modules (Figure 4). Each module will consist of individual processes that must be performed to successfully complete the main module, and another module can be accessed.

The Risks module defines the risks that can jeopardize the assembly plan. Whether these risks are defined by the company itself on the basis of historical data or it uses studies that have defined the most common risks.

In the Simulation module, a simulation project is used and to create a simulation model of the assembly workplace (or assembly workplaces according to the company's requirements) and risk experiments are created. Based on the results of the simulation, the company will know approximately what impact the risk will have on the assembly (assembly plan). Then the measures are proposed, which are simulated and from the obtained results we proceed to the last module Action plan in which the action plan will be created. The action plan will describe how to proceed in the event of a risk (what is to be done, who is responsible for it and the time to individual actions).

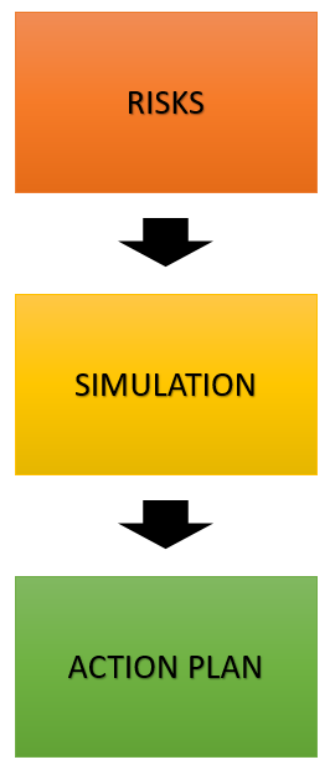

Figure 4-Main modules of the proposed methodology [authors].

\section{CONCLUSION}

ERP products are used extensively. The main manufacturers of information systems, which have been established since the early ' 80 s, began to write a history of the development of ERP systems. The ERP system contains a set of primary functions and modules that integrate every business department around the world by providing real-time control of data and processes. In the past, ERP systems have only been applied to large companies, but in recent decades they have also focused on small and medium-sized enterprises. 
Currently, there are ERP III systems in which Business Intelligence (BI) is improved, which helps companies collect, analyse data, transform it into an interpretable form and use elements of Industry 4.0 (Cloud, IloT).

Although ERP III uses industry 4.0 technologies, there is still a lack of a module for risk identification and analysis and the subsequent creation of action plans for these risks. In the event of risks, action plans would be activated to eliminate or mitigate the negative effects of these risks. Only in ERP V or ERP VI is it assumed that artificial intelligence can handle this task.

At present, companies must be in good shape and able to respond immediately to risks that could risk production and to take these risks into account in the planning phase. From this point of view, the acquired knowledge was used to develop a dissertation thesis, which deals with the design of a methodology that will protect the assembly plan from the risks that may occur. At present, companies must be in good shape and able to respond immediately to risks that could jeopardize production and to take these risks into account in the planning phase. The proposed methodology consists of three main modules, which are briefly described in subchapter 5.1 Proposed methodology. The methodology is applied to the created assembly plan, which will result in the creation of action plans that will prevent the disruption or cessation of the assembly plan in the event of a risk.

Further research will develop individual modules and create the necessary links between them. A module will also be designed to respond to risks that the company did not anticipate at the beginning of the proposed methodology in the Risks module.

\section{Acknowledgments}

This work was supported by the KEGA Agency under the Contract no. 022ŽU4/2018.

\section{References}

[1] KASEM, R. Surveying Systems of Enterprise Resource Planning. Researchgate. [online]. 2017, [cit. 2020-08-04]. Dostupné z: https://www.researchgate.net/publication/315680017_Surveying_Systems_o f_Enterprise_Resource_Planning

[2] GREGOR, M., MIČIETA, B., BUBENÍK, P. Plánovanie výroby. Žilina : ŽU v Žiline v EDIS, 2005. $173 \mathrm{~s}$. ISBN 80-8070-427-9.

[3] KURBEL, K. E. Enterprise Resource Planning and Supply Chain Management - Functions, Business Processes and Software for Manufacturing Companies. 1st ed. Berlin : Springer, 2013. 359 p. ISBN 9783-642-31573-2.

[4] HERČKO, J., FUSKO, M., KOTOROVÁ SLUŠNÁ, L'. Concept of the Factories of the Future in Slovak industrial companies. In: Mobility loT 2018, 
5th EAI International Conference on Smart Cities within SmartCity360 Summit, 2018.

[5] RASHID, A. M. et al. The Evolution of ERP Systems: A Historical Perspective. [online]. Idea Group Publishing, 2002 [cit. 2020-02-04]. Accessed from: https://faculty.biu.ac.il/ shnaidh/zooloo/nihul/evolution.pdf

[6] Evolution of Enterprise Resource Planning. [online]. 2020 [cit. 2020-02-04]. Accessed from: https://www.brainkart.com/article/Evolution-of-EnterpriseResourcePlanning 7316/

[7] BARRETT, A. Information Systems within the Organization. [online]. 2019 [cit. 2020-02-04]. Accessed from: https://slideplayer.com/slide/13762148/

[8] JOSHI, V. The history of ERP systems- from the beginning to now. [online]. Beyond Accounting, Business Solutions and You, 2017 [cit. 2020-02-04]. Accessed from: http://www.versaccounts.com/blog/the-history-of-erpsystems/

[9] Business Intelligence (BI) in ERP Systems Has Never Been More Valuable. [online]. Abas USA, 2018 [cit. 2020-02-04]. Accessed from: https://abaserp.com/en/news/business-intelligence-erp-systems

[10] SUKHOBOKOV, A. Business analytics and AGI in corporate management systems. [online]. Researchgate, 2018 [cit. 2020-01-09]. Accessed from: https://www.researchgate.net/publication/329574244 Business analytics a nd AGI in corporate management systems/references 